\title{
Postfire regeneration of Aleppo pine - the temporal pattern of seedling recruitment
}

\author{
Evangelia N. Daskalakou ${ }^{1} \&$ Costas A. Thanos ${ }^{2, *}$ \\ ${ }^{1}$ National Agricultural Research Foundation, Institute of Mediterranean Forest Ecosystems and Forest Products \\ Technology, Terma Alkmanos str., 11528 Athens, Greece; ${ }^{2}$ Department of Botany, Faculty of Biology, University of \\ Athens, 15784 Athens, Greece; *Author for correspondence (email cthanos@biol.uoa.gr)
}

Received ; accepted in revised form

Key words: Pinus halepensis, Seedling emergence, Seedling establishment, Seedling density, Seedling mortality

\begin{abstract}
The temporal dynamics of Pinus halepensis seedling emergence, density and survival were studied in detail during the first postfire year, in five Aleppo pine forests of Attica (Stamata, Villia, Avlona, Kapandriti and Ag. Stefanos; burned in June 1990, July 1990, September 1991, September 1992 and July 1993, respectively). The timing of emergence and establishment of Aleppo pine seedlings was found to be correlated with the prevailing meteorological conditions - mainly rainfall and to a lesser degree temperature. In most cases, seed germination and seedling emergence took place in a "single massive wave" (resembling a right-skewed normal distribution), shortly after the onset of the first postfire rainy season, (Stamata, Villia and Avlona; 80-90\% of the total cohort emerged during November-December). However, variations in the timing and spread of this pattern were observed in Agios Stefanos and Kapandriti. In the former, there was a considerable delay of seedling emergence ( $80 \%$ by the end of February); in the latter, a bimodal pattern was found (peaks in December-February and March-April). The dynamics of pine seedling mortality (which amounted to a yearly $23-50 \%$ of the total cohort) showed two major, discrete peaks of almost equal importance during the first postfire year: at the initial seedling establishment phase (in the winter) and during the dry summer.
\end{abstract}

\section{Introduction}

Fire has apparently acted as a powerful agent of natural selection in the evolution and adaptation of the Mediterranean flora as well as in shaping the Mediterranean landscapes into the present, mosaic-like patterns with diverse levels of regeneration and degradation (Le Houerou 1987; Naveh 1991; Thanos 1999). Fire resilience of Mediterranean-type ecosystems and pine forests in particular is well documented; postfire regeneration of a mature forest usually takes place naturally and prolifically, provided that no secondary destructive disturbance, such as an additional fire or grazing, occurs (Trabaud et al. 1985; Dafis 1987; Thanos et al. 1989; Moravec 1990; Thanos and Marcou 1991; Thanos and Marcou 1993; Ne'eman et al. 1993; Saracino and Leone 1993; Saracino et al. 1993; Kazanis and Arianoutsou 1996; Thanos et al.
1996; Herranz et al. 1997; Ne'eman 1997; Tsitsoni 1997; Thanos 1999; Arianoutsou and Ne'eman 2000; Leone et al. 2000; Thanos and Daskalakou 2000; Trabaud 2000; Saracino and Leone 2001; De las Heras et al. 2002; Retana et al. 2002; Verroios and Georgiadis 2002; Kazanis and Arianoutsou in press).

Pinus halepensis Mill. (Aleppo pine) is the dominant, coastal (low-altitude) Mediterranean, pine tree of Greece; its flammable forests cover a large fraction $(26 \%)$ of the Greek coniferous forests or a total area of 372,000 ha - almost 3\% of the total area of Greece (Daskalakou 1996). Aleppo pine has evolved several adaptive mechanisms in response to the "catastrophic" fire events; being an obligate reseeder (usually killed by a typical fire), this pine depends for its survival upon a very powerful regenerative capacity, based on both the yearly production of prolific seed crops and the safeguarding of a fraction of its seed output in a 
cumulative canopy seed bank, within the serotinous cones: a double or bet-hedging strategy of regeneration (Daskalakou and Thanos 1996; Nathan and Ne'eman 2000). Postfire regeneration depends exclusively upon the canopy seed bank as a result of both the transient character of the soil bank of pine seeds and the destruction of all seeds that happen to be found on or near the soil surface during the fire. The postfire seed rain in a mature Aleppo pine forest in Attica was estimated to amount to several hundred seeds per $\mathrm{m}^{2}$ (Daskalakou and Thanos 1996). Seed germination and seedling recruitment are well adapted to exploit the postfire conditions and promptly colonize the open, burned areas (Thanos and Skordilis 1987; Skordilis 1992; Skordilis and Thanos 1995; Thanos 2000).

Seed germination and seedling emergence of Aleppo pine take place almost exclusively during the first postfire wet season (Daskalakou 1996; Thanos 1999). The principal aim of the present study has been the detailed, quantitative assessment of the temporal pattern of Aleppo pine seedling recruitment during the first postfire year. Several different cases of burned forests, in Attica, were monitored and seedling emergence, seedling density, mortality and overall establishment were investigated throughout the first postfire year.

\section{Materials and Methods}

Field data were collected from five, recently burned, Aleppo pine (Pinus halepensis) forests in the prefecture of Attica, Greece. More specifically, the burned forests studied are scattered on all the important mountains of Attica: Stamata and Ag. Stefanos (Mt. Pendeli), Kapandriti (Mt. Mavrovouni), Avlona (Mt. Parnes) and Villia (Mt. Pateras). The study areas are located to the NE-NW of the city centre of Athens at a distance of 22, 23, 31, 29 and $42 \mathrm{~km}$, respectively, and at an altitude of 410, 300, 400, 480 and $550 \mathrm{~m}$ a.s.l. The soils in Stamata, Agios Stefanos and Kapandriti are schists and tertiary deposits while the remaining two study areas are covered by hard limestone, a typical substrate of many Mediterranean ecosystems. The wildfires that burned entirely those Aleppo pine forests took place, as usual, during summertime, in July (Stamata and Villia 1990; Agios Stefanos1993) and in September (Avlona 1991; Kapandriti 1992).

In each burned area, assessment of postfire regeneration was carried out on five permanent experimental plots - transects, $10 \mathrm{~m}$ long by $1 \mathrm{~m}$ wide (not very different from the $8 \mathrm{~m}$ by $2 \mathrm{~m}$ rectangles proposed by Corona et al. 1998). These plots were established at randomly selected sites, of varying exposures and slopes of the burned forests, soon after the fire and before the onset of the rainy season. Field observations and measurements of Aleppo pine seedling emergence, establishment, density and survival/mortality took place at almost monthly intervals throughout the first postfire year, October 1 to September 30 (Daskalakou 1996). All study plots were mapped in detail; each emerging Aleppo pine seedling inside the plots was recorded and tagged with a coloured plastic ring or a numbered label and monitored for survival throughout the observation period.

To assess the conditions prevailing during the particular postfire seasons, the data of two major Meteorological Stations were used. These stations, located at an altitude of 30 and $237 \mathrm{~m}$ a.s.1., respectively, in Eleusis and Tatoi airports, are the closest to the experimental sites (the former to Villia and the latter to the other four areas studied). For the entire study period, 1990-1994, daily precipitation and mean monthly values of the daily mean, maximum and minimum temperatures were provided by the National Meteorological Service of Greece (EMY).

\section{Results}

\section{Seedling emergence}

Aleppo pine seedling emergence during the first postfire year, for each burned forest studied, are illustrated as frequency histograms in Figure 1. A total number of 250, 188, 228, 265 and 240 Aleppo pine seedlings (in Stamata, Villia, Avlona, Kapandriti and Agios Stefanos, respectively) were recorded in the total area of $50 \mathrm{~m}^{2}$ in all five transects. As shown by the arrows in Figure 1, a significant fraction of each cohort (79.6, $79.8,87.3,71.3$ and $86.3 \%$, respectively) emerged and initially established within 2 months from the time of first field appearance of the pine seedling cohort. However, the bulk of seedling emergence was complete from as early as the start of December (Figure 1, Avlona) to as late as the end of February (Figure 1, Ag. Stefanos). In both Kapandriti and Ag. Stefanos a remarkable delay of seedling emergence occurred in comparison to the other three sites and, in addition, there was a second, much smaller, peak (or tail) in emergence by the end of spring.

In Figure 2, the dynamics of seedling emergence and establishment are illustrated in the same graphs 

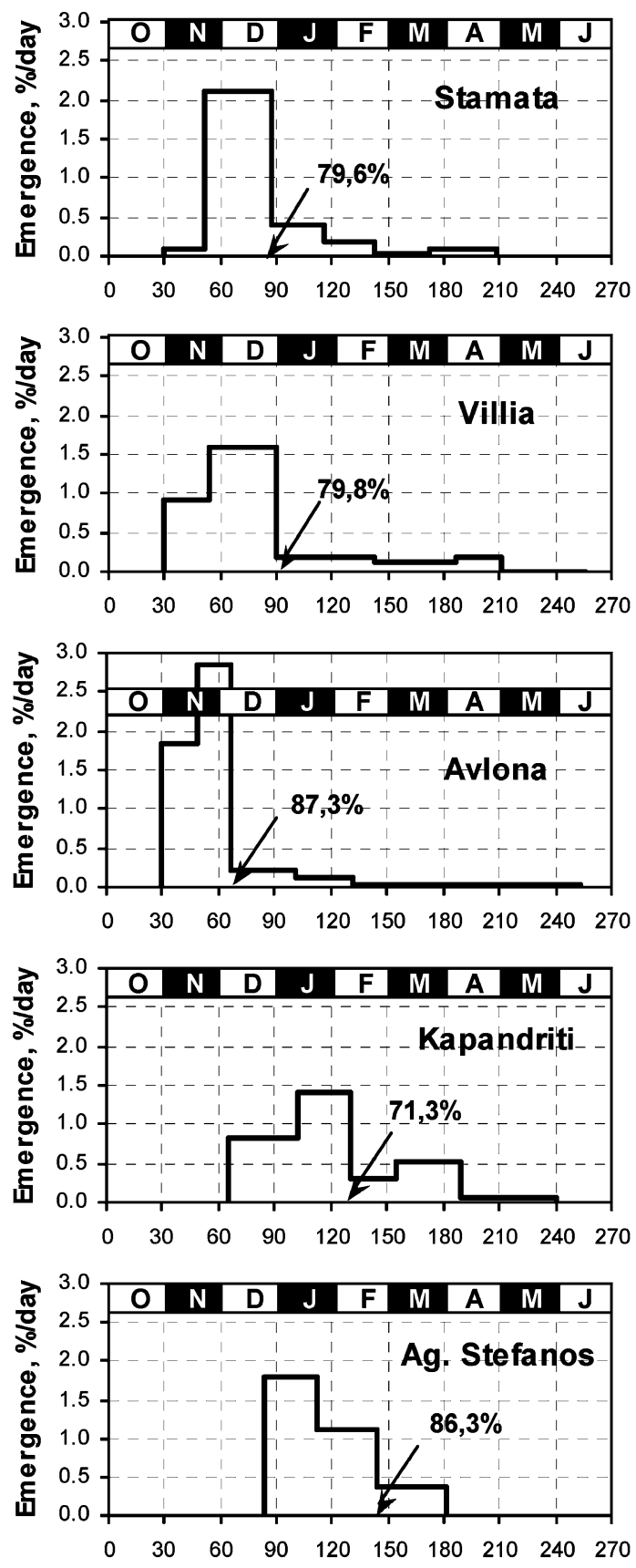

Time, days

Figure 1. The temporal pattern of Pinus halepensis seedling emergence during the first postfire year in five pine forests of Attica (burned in different years). Values correspond to pine seedlings (found newly-emerged at specific observation dates, in a total area of $50 \mathrm{~m}^{2}$ of five permanent transects) expressed as a percentage of the total number of seedlings (which appeared during the first postfire year) per day (for the period between consecutive measurements). The arrows and respective values denote the time and quantity (as percentage of the total cohort) at the end of the main period of seedling emergence. Time 0 is October 1 (the onset of the first, postfire hydrological year).
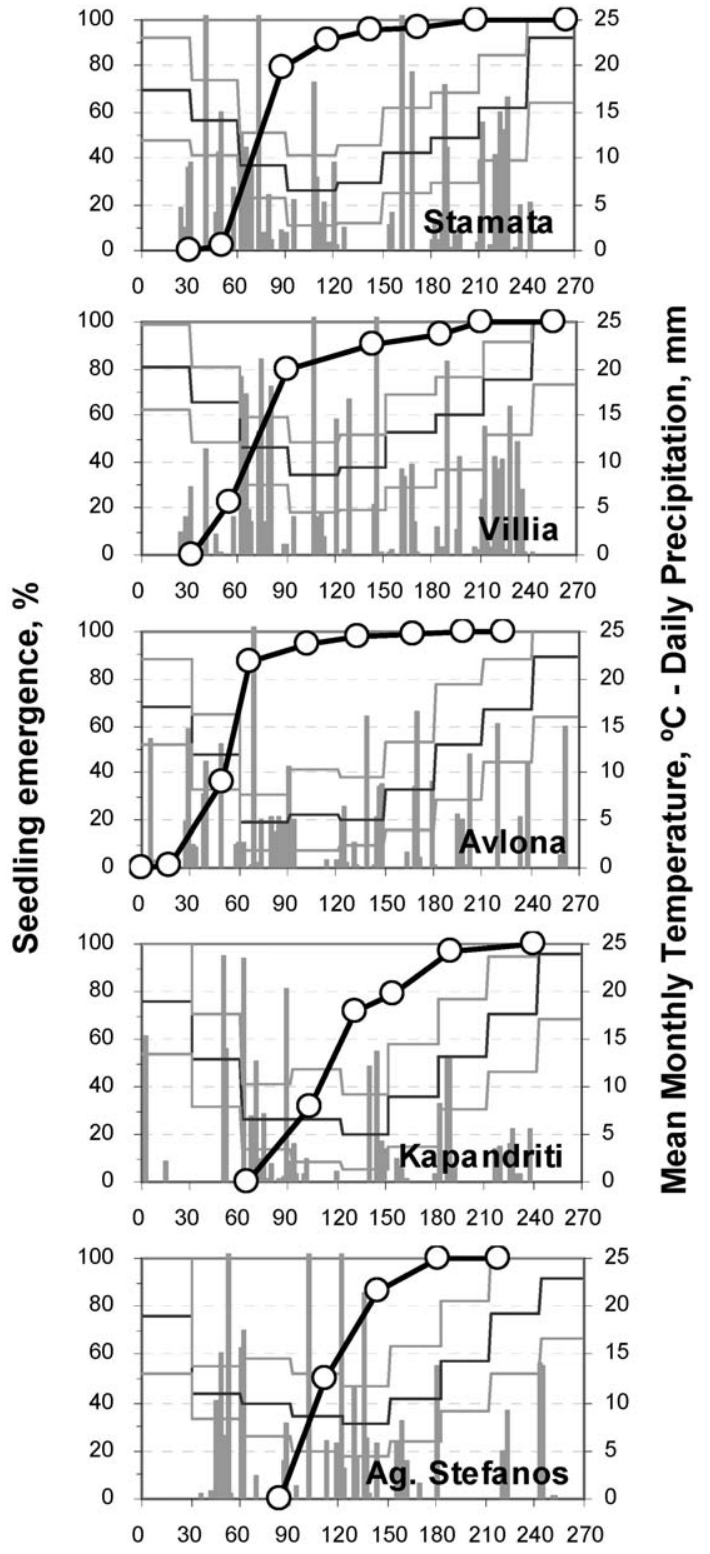

Time, days

Figure 2. The cumulative time course of Pinus halepensis seedling emergence during the first postfire year in five pine forests of Attica (burned in different years). The step-like curves represent the monthly average values of maximum, mean and minimum daily temperatures recorded at the closest meteorological station for the period studied. The vertical bars represent daily precipitation. Time 0 is October 1 (the onset of the first, postfire hydrological year). 
with the daily precipitation and the mean monthly temperatures, for the corresponding, first postfire year. Seedling emergence is converted into a cumulative curve and all five curves follow sigmoid kinetics with almost identical slopes (with the exception of a somewhat slower pace in Kapandriti). In the first two cases (Stamata and Villia), the rainy season began at the end of October and the bulk of seedling emergence $(80 \%$ of the total cohort) was completed almost two months later. A significant amount of precipitation during the first rainy week (26 and $16 \mathrm{~mm}$, respectively) obviously triggered pine seed germination; subsequent pine seedling emergence was facilitated by the ensuing wet conditions and the average temperatures for the season - mean monthly temperatures around 15 and $10{ }^{\circ} \mathrm{C}$ for the first (November) and second (December) month, respectively. In the third case of Figure 2 (Avlona), the rainy season started early in October and by the end of the month the precipitation already amounted to $41 \mathrm{~mm}$, while the mean temperatures during the first two rainy months were (similarly to the previous case) 15 and $10^{\circ} \mathrm{C}$ (October and November, respectively). Almost $90 \%$ of the total cohort had emerged by the beginning of December when the mean temperature dropped to $5{ }^{\circ} \mathrm{C}$. In the fourth case (Kapandriti), a short rainy spell early in October was followed by an extended dry period till the end of November; cool temperatures (below 10 ${ }^{\circ} \mathrm{C}$ ) prevailed during the delayed rainy season and pine seedling emergence was clearly slowed down, not to be completed before the end of March. A similar delay was also observed in the last case (Agios Stefanos) despite the fact that the rainy season began somewhat earlier than in the previous case.

\section{Seedling mortality and survival}

Throughout the first postfire year, the total toll of dead seedlings, in each of the five forest sites, respectively, amounted to (in parenthesis the total number of seedlings emerged and the percentage of mortality): 125 (250, 50\%), 89 (188, 47.3\%), 86 (228, 37.7\%), 61 $(265,23 \%)$, and $69(240,28.8 \%)$. Therefore, the overall annual mortality of pine seedlings ranged between 23 and $50 \%$ with an average $( \pm \mathrm{SE})$ of $37.4 \pm 5.2 \%$ $(n=5)$. The dynamics of seedling mortality during the first postfire year, for each of the five sites studied, are shown in Figure 3. Two periods of pronounced mortality are quite clearly distinguishable in each frequency histogram of Figure 3. During the first period ("the early establishment phase") which covers the whole
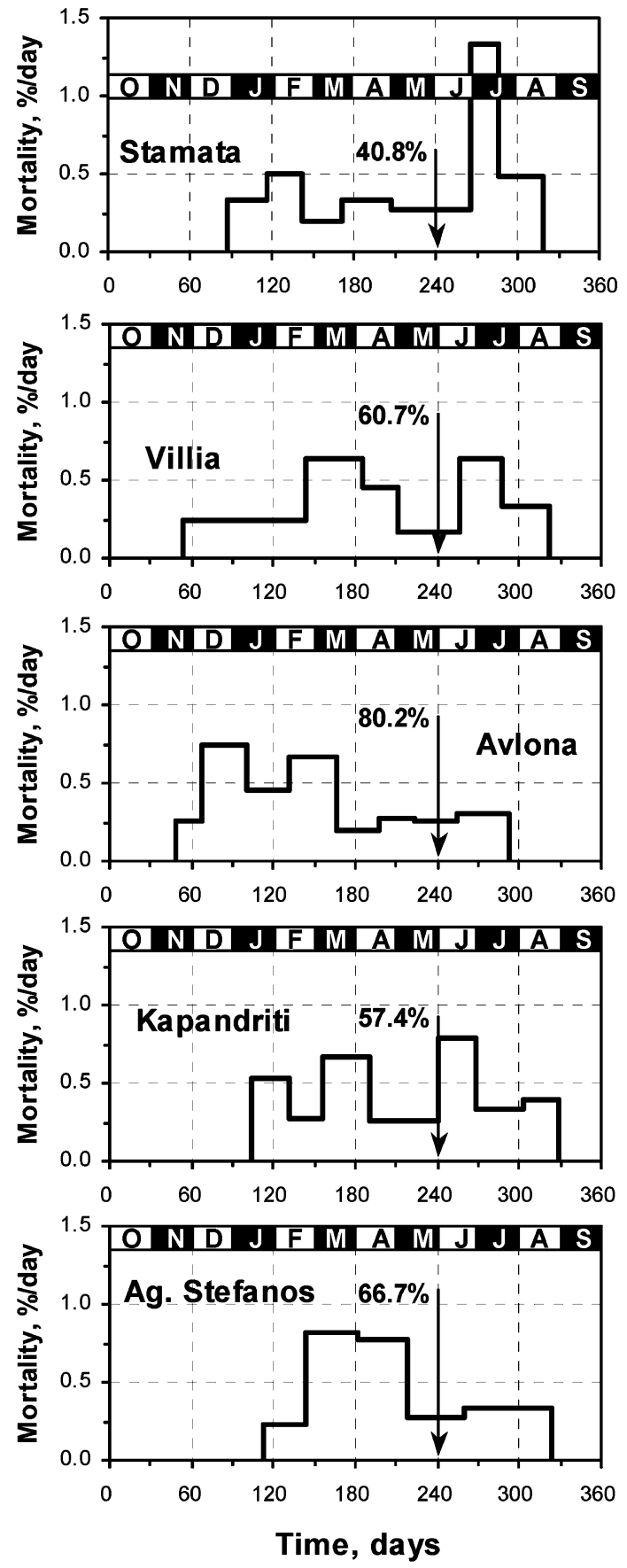

Figure 3. The temporal pattern of Pinus halepensis seedling mortality during the first postfire year in five pine forests of Attica (burned in different years). Values correspond to pine seedlings (found dead at specific observation dates, in a total area of $50 \mathrm{~m}^{2}$ of five permanent transects) expressed as a percentage of the total number of non-surviving seedlings (during the first postfire year) per day (for the period between consecutive measurements). The arrows (at the end of May) and respective values denote the fraction of seedlings (as percentage of the total number of non-surviving seedlings) perished during the first postfire wet season (winter and spring). Time 0 is October 1 (the onset of the first, postfire hydrological year). 
rainy season (till the end of spring, May 31, marked by the arrows in the graphs), mortality ranged between 40.8 and $80.2 \%$ of the annual total with an overall average $( \pm S E)$ of $61.2 \pm 6.4 \%(n=5)$. On the other hand, mortality during the first postfire summer ("the drought stress phase") ranged between 19.8 and 59.2\% of the annual total with an overall average $( \pm \mathrm{SE})$ of $38.8 \pm 6.4 \%(\mathrm{n}=5)$.

\section{Seedling population dynamics}

The time courses of pine seedling density (Figure 4) show, in all cases, an initial steep increase during late autumn and winter followed by a plateau and a relatively slight decrease thereafter. Despite their diverging timing, the sigmoid-like, initial parts of the curves showed similar slopes; in the linearlike, decreasing parts of the curves the slopes were markedly similar, almost identical. Maximum density values ranged between 2.9 and 4.3 seedlings $\cdot \mathrm{m}^{-2}$; the maximum was observed as early as the beginning of December (Avlona) or as late as April-May (Kapandriti). The mean maximum density for all five sites was $4.0 \pm 0.3$ seedlings $\cdot \mathrm{m}^{-2}(\mathrm{n}=5)$ while the minimum density scored at the end of the observation period (end of September) was $2.7 \pm 0.4$ seedlings $\cdot \mathrm{m}^{-2}$ $(n=5)$.

\section{Discussion}

Aleppo pine postfire seedling recruitment takes place, almost exclusively, during the first growth season after a wildfire fully consumes a mature forest (Thanos 1999; Arianoutsou and Ne'eman 2000; Leone et al. 2000); during the subsequent years only a sporadic seedling emergence has been observed in a few cases (Daskalakou 1996; Herranz et al. 1997). From the point of view of the fire-recruiter / fire-persistent syndromes (Keeley 1991), Aleppo pine is characterised as a fire-recruiter species and is anticipated to recruit a new postfire seedling cohort exclusively during the first postfire year. However, it must be borne in mind that this species can also regenerate in fire-free conditions (as mentioned earlier in the introduction), particularly in forest gaps or in adjacent, open or disturbed sites. The present work is the first one that aims at a detailed investigation of seedling recruitment dynamics during the first postfire year, by far the most critical period for the regeneration of a pine forest. In all five forests of Attica, studied during four different, consecutive years, markedly similar sets of data on seedling emergence, mortality and population density dynamics were obtained.

In all five cases, seed germination and seedling emergence took place in a "massive wave" shortly after the onset of the first postfire rainy season. The bulk of germinable seeds (derived from the canopy seed bank) were transformed into seedlings entirely during winter (November-December) while in two cases a small, additional portion emerged in spring, as well. Smoothed curves of the seedling emergence frequency histograms (Figure 2) are presented in Figure 5. All curves seem to follow right-skewed normal distribution dynamics while in a single exceptional case (Kapandriti) there was a bimodal pattern with a second, minor spring peak. Therefore, it is confirmed that pine seed germination and subsequent establishment occur early in the natural, postfire succession of vegetation. This conclusion is in close agreement with the characteristics of Pinus halepensis seed germination revealed by laboratory experiments: a relatively cool, temperature range of germination $\left(5-25^{\circ} \mathrm{C}\right)$ with an optimum at around $15-20{ }^{\circ} \mathrm{C}$ and a maximum final germination value (80-100\%) attained within 2-3 weeks in either darkness or white light (Thanos 2000). These characteristics would normally result in autumn germination and are considered as an adaptation to the Mediterranean climate. The autumn-germination timing confers an obvious ecological advantage, in that seed germination is accomplished relatively early during the rainy season and, consequently, the developing seedlings can take advantage of most of the wet season (mild winter and following spring) before the drought of the Mediterranean summer (Thanos and Skordilis 1987; Skordilis 1992; Skordilis and Thanos 1995; Thanos 2000). In the closely related eastern Mediterranean pine, Pinus brutia, both laboratory predictions and preliminary field results show that this pattern may be modified in certain regions with more severe winters: the seedling recruitment profile is shifted to late winter or early spring (irrespectively of water availability), perhaps as a frost-avoiding mechanism for the vulnerable seedlings (Skordilis and Thanos 1995).

A significant lag (of nearly one month) was obtained when the dynamics of seedling emergence were correlated with daily precipitation (Figure 2). At optimal, laboratory conditions, Aleppo pine seed germination begins about one week after onset of imbibition and is completed within another two weeks (Thanos and Skordilis 1987; Daskalakou and Thanos 


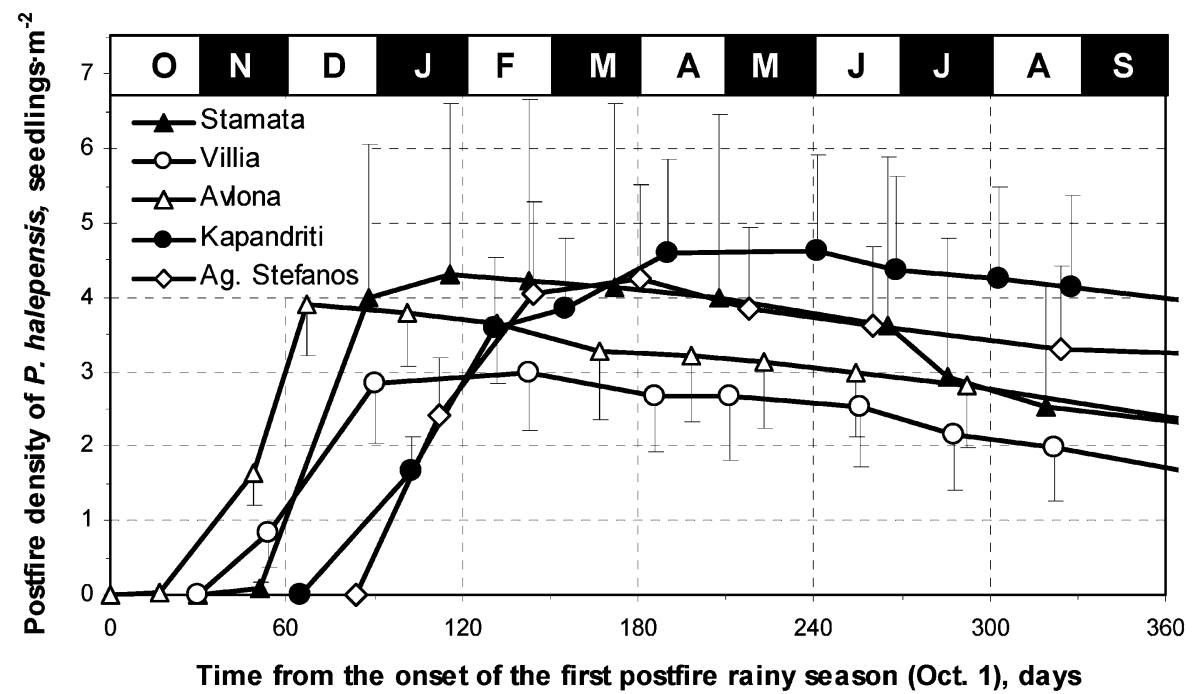

Figure 4. The dynamics of Pinus halepensis seedling density, during the first postfire year, in five pine forests of Attica (burned in different years). The vertical bars represent $1 \mathrm{SE}$ ( $\mathrm{n}=5$ for each value).

1996; Thanos 2000). Under the suboptimal, temperature conditions in the field, a second week should be added to the initial "lag phase" of germination and another one to two weeks for the early seedling growth until the stage of cotyledon expansion (Skordilis 1992). Allowing also some time (one to two weeks) for the actual counting of germination in the field, we arrive at a lag of about one month, after the start of the rainy season until the first recording of pine emergence. In the first three cases, the total duration of seedling emergence lasted about four to six weeks, much longer again than an optimal germination curve in the lab (which requires one to two weeks, from early- to late-germinating seeds). In the remaining two sites, a considerable delay for the completion of emergence was observed; this delay may be attributed to the relatively low temperatures which prevailed during the seedling emergence period.

In regard to seedling mortality it has been assumed, almost unanimously, that the most prominent reason of mortality is summer drought (e.g., Trabaud 1988). On several occasions, it was found that the first postfire summer is by far the most crucial period for the survival of seedlings in both Aleppo and East Mediterranean pines (e.g., Saracino et al. 1993; Thanos et al. 1989). However, another decisive season (the importance of which is usually disregarded) is the first part of the rainy period, immediately after the fire, when germination and early seedling development and establishment take place. During a three-year-long, postfire regeneration study of Aleppo pine in Mt Parnes (Attica), Thanos et al. (1996) reported the overall highest value of mortality during the first postfire summer (June-September), the second highest being recorded during the first postfire spring (March-June). However, the previous study started after the postfire seedling recruitment was terminated (in March) and did not include the germination period. The present study is the first one that covers the whole recruitment phase from the onset of the first postfire wet season. Two periods of pronounced mortality are discernible (Figure 3); on average, the relative importance of mortality during the "early establishment phase" seems higher than during the "drought stress phase" (61.2 to $38.8 \%$ ). However, if mortality values are estimated on the actual number of seedlings remaining alive (and not for the total of all emerged seedlings) the percentages of mortality are not statistically different: $22.4 \pm 3.2 \%(n=5)$ for the former phase and $19.4 \pm 5.2 \%(n=5)$ for the latter one. Therefore, it is concluded that both phases are of almost equal importance for seedling survival; nevertheless, a final reservation concerns the possible underestimation of mortality during the first phase, due to seedlings that either died at very initial stages and went unnoticed or emerged after an observation date and failed to survive until the next one.

The mortality values reported in the literature for Aleppo pine seedlings show a large diversity, evidently the result of both the differences in the forests burned and the particular conditions prevailing during the postfire years. Mortality percentages ranged from 


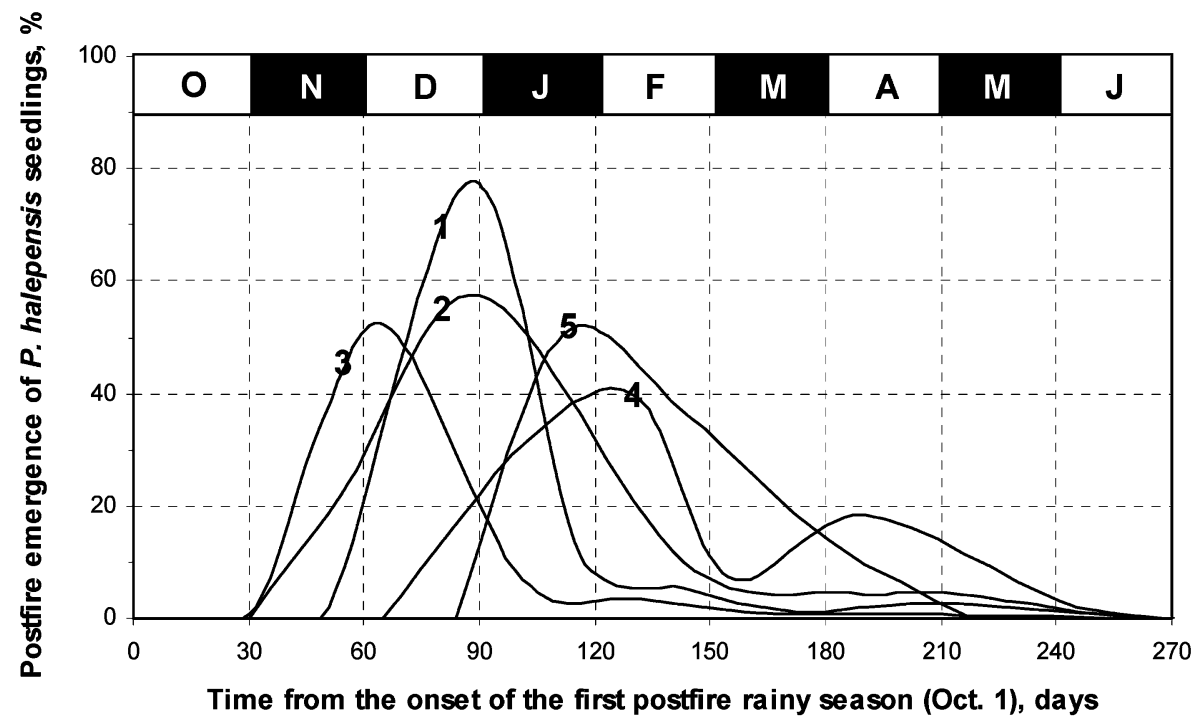

Figure 5. Smoothed distribution curves of Pinus halepensis seedling emergence over the first postfire year. Each curve corresponds to a burned forest of Attica; 1: Stamata, 2: Villia, 3: Avlona, 4: Kapandriti and 5: Agios Stefanos.

as low as $11 \%$ after three years (Trabaud 1988) to as high as $50 \%$ and $65 \%$ during the first postfire establishment period (Thanos et al. 1996; Saracino et al. 1993; respectively). In a recent work (Pausas et al. 2003) mortality was found to range widely in response to fire severity and lowest values were observed after a fire of high severity (ca $40 \%$ after 2.5 years). In the present study, mortality during the first postfire year (12-14 months after the wildfire and including the generally overlooked establishment phase) ranged considerably among the five sites $(23-50 \%)$ and attained on average (37.4\%) a comparable level to that of most reports mentioned above.

In three investigated locations of the present study, the maximum value of pine seedling density (2.94.3 seedlings $\cdot \mathrm{m}^{-2}$ ) was recorded during the winter months (December-February) while in the remaining two, maximum density (4.2-4.6 seedlings $\mathrm{m}^{-2}$ ) was observed in spring (April-May). The overall, average maximum density measured was $4.0 \pm 0.3$ seedlings $\cdot \mathrm{m}^{-2}$ while the minimum density scored at the end of the observation period (end of September) is $2.7 \pm 0.4$ seedlings $\cdot \mathrm{m}^{-2}$. Related studies on the regeneration of burned Aleppo pine forests in southern France (Trabaud et al. 1985) showed a quite low value of density $\left(0.1\right.$ seedlings $\left.\cdot \mathrm{m}^{-2}\right)$ that was correlated to both burned pine tree density and the distance to the unburned forest. In another case, Aleppo pine seedling density was found similarly low (0.07 seedlings $\left.\cdot \mathrm{m}^{-2}\right)$ in the first postfire June (Trabaud 1988). In burned forests of northwest Algeria, the sapling density varied between $0.16-0.23$ seedlings $\cdot \mathrm{m}^{-2}$, two years after fire (Moravec 1990). In South African burned Aleppo pine stands, 6.6-13.4 seedlings $\cdot \mathrm{m}^{-2}$ were counted eight months after fire (Richardson 1988). In a diachronic study of $P$. halepensis postfire dynamics in Attica (Thanos et al. 1996) density values markedly similar to those of the present work were observed: a maximum density of $5.51 \pm 0.36$ seedlings $\cdot \mathrm{m}^{-2}$, nine months after fire and $2.40 \pm 0.20$ seedlings $\cdot \mathrm{m}^{-2}$ at the end of the first postfire summer $\left(1.33 \pm 0.10\right.$ seedlings $\cdot \mathrm{m}^{-2}$, 39 months after fire). In a similar study in southeastern Spain (Herranz et al. 1997), a maximum density of 0.66 seedlings $\cdot \mathrm{m}^{-2}$ was observed nine months after fire (which declined to 0.24 seedlings $\cdot \mathrm{m}^{-2}, 39$ months after fire). Similarly low density values were reported in a recent work in eastern Spain (Pausas et al. 2003): an average of 0.45 and 0.27 seedlings $\cdot \mathrm{m}^{-2}$ eight months and 2.5 years after fire, respectively. Much more higher density variation was reported in Italy (Saracino and Leone 1993) and on Mt Carmel in Israel (Ne'eman et al. 1993) as well as for Pinus brutia on Greek islands of Thasos (Spanos 1992; Spanos et al. 2000) and Samos (Thanos and Marcou 1991; Thanos and Marcou 1993).

In conclusion, and on the basis of the quite similar dynamics in all five investigated sites of the present study, the pattern of density dynamics during the first postfire year comprises two consecutive curves: a first, sigmoid part, timed according to the prevailing met- 
eorological conditions, and a second, linear part with a rather slight, negative slope which starts immediately after the bulk of seedling recruitment has been finished (i.e. sometime between December and May and covering the whole observation period till the end of September).

\section{Acknowledgements}

This work was carried out in the framework of research projects funded by the European Union (PROMETHEUS EV5V-CT94-0482) and the General Secretariat of Research and Technology, Greece (PENED 91/824). We thank the National Meteorological Service of Greece (EMY) for providing the meteorological data. We are also thankful to Roberto Calamassi, Vasilios Papanastasis, Ken Thompson and Margarita Arianoutsou, guest editor of the volume, for helpful comments and suggestions on an earlier version of the manuscript.

\section{References}

Arianoutsou M. and Ne'eman G. 2000. Post-fire regeneration of natural Pinus halepensis forests in the east Mediterranean basin. In: Ne'eman G. and Trabaud L. (eds), Ecology, Biogeography and Management of Pinus halepensis and P. brutia Forest Ecosystems in the Mediterranean Basin. Backhuys Publishers, Leiden, The Netherlands, pp. 269-289.

Corona P., Leone V. and Saracino A. 1998. Plot size and shape for the early assessment of post-fire regeneration in Aleppo pine stands. New Forests 16: 213-220.

Dafis S.A. 1987. Ecology of Aleppo and Brutia pine forests (in Greek). In: Forests of Aleppo and Brutia pine, Proceedings of Chalkis Meeting, 30 September - 2 October 1987, pp. 17-25.

Daskalakou E.N. 1996. Ecophysiology of the postfire regeneration in Aleppo pine (Pinus halepensis) forests (in Greek). $\mathrm{PhD}$ Thesis, University of Athens, Athens, Greece.

Daskalakou E.N. and Thanos C.A. 1996. Aleppo pine (Pinus halepensis) postfire regeneration: The role of canopy and soil seed banks. International Journal of Wildland Fire, 6: 59-66.

De las Heras J., Martinez-Sanchez J.J., Gonzalez-Ochoa A.I., Ferrandis P. and Herranz J.M. 2002. Establishment of Pinus halepensis Mill. saplings following fire: effects of competition with shrub species. Acta Oecologica 23: 91-97.

Herranz J.M., Martinez-Sanchez J.J., Marin A. and Ferrandis P.1997. Postfire regeneration of Pinus halepensis Miller in a semi-arid area Albacete province (southeastern Spain). EcoScience 4: 86-90.

Kazanis D. and Arianoutsou M. 1996. Vegetation structure in a postfire successional gradient of Pinus halepensis forests of Attica. International Journal of Wildland Fire 6: 83-91.

Kazanis D. and Arianoutsou M. in press. Long term vegetation dynamics in Pinus halepensis forests of Central Greece: a functional group approach. Plant Ecology.
Keeley J.E. 1991. Seed germination and life history syndromes in the California chaparral. The Botanical Review 57: 81-116.

Le Houerou H.N. 1987. Vegetation wildfires in the Mediterannean Basin: evolution and trends. Ecologia Mediterranea 13: 13-24.

Leone V., Borghetti M. and Saracino A. 2000. Ecology of postfire recovery in Pinus halepensis in southern Italy. In: Trabaud L. (ed.), Life and Environment in the Mediterranean, Advances in Ecological Sciences 3. WIT Press, Southampton, UK, pp. 129-154.

Moravec J. 1990. Regeneration of N.W. African Pinus halepensis forests following fire. Vegetatio 87: 29-36.

Nathan R. and Ne'eman G. 2000. Serotiny, seed dispersal and seed predation in P. halepensis. In: Ne'eman G. and Trabaud L. (eds), Ecology, Biogeography and Management of Pinus halepensis and P. brutia Forest Ecosystems in the Mediterranean Basin. Backhuys Publishers, Leiden, The Netherlands, pp. 105-118.

Naveh Z. 1991. The role of fire in Mediterranean vegetation. Botanica Chronica 10: 385-405.

Ne'eman G. 1997. Regeneration of natural pine forest - Review of the work done after the 1989 fire in Mount Carmel, Israel. International Journal of Wildland Fire 7: 295-306.

Ne'eman G., Lahav H. and Izhaki I. 1993. The resilience of vegetation to fire in an east-Mediterranean pine forest on Mount Carmel, Israel: the effect of post-fire management. In: Trabaud L. and Prodon R. (eds), Fire in Mediterranean Ecosystems. Commission of the European Communities, Brussels, pp. $127-140$.

Pausas J.G., Ouadah N., Ferran A., Gimeno T., Vallejo R. 2003. Fire severity and seedling establishment in Pinus halepensis woodlands, eastern Iberian Peninsula. Plant Ecology 169: 205-213.

Retana J., Espelta J.M., Habrouk A., Ordonez J.L. and de SolaMorales F. 2002. Regeneration patterns of three Mediterranean pines and forest changes after a large wildfire in northeastern Spain. EcoScience 9: 89-97.

Richardson D.M. 1988. Age structure and regeneration after fire in a self-sown Pinus halepensis forest on the Cape Peninsula, South Africa. South African Journal of Botany 54: 140-144.

Saracino A. and Leone V. 1993. Natural regeneration 2 and 4 years after fire of Pinus halepensis Miller in dunal environment. In: Trabaud L. and Prodon R. (eds), Fire in Mediterranean Ecosystems. Commission of European Communities, Brussels, pp. $141-150$.

Saracino A. and Leone V. 2001. Strategie di sopravvivenza al fuoco e meccanismi di recupero post-incendio in ambiente mediterraneo: il caso delle pinete di pino d' Aleppo. Monti e Boschi 52: $38-46$.

Saracino A., Leone V. and De Natale F. 1993. Permanent plots for the study of natural regeneration after fire of Pinus halepensis Miller in dunal environment. Annali di Botanica (Roma) 51: 209-217.

Skordilis A. 1992. Seed germination and seedling development in Pinus halepensis and P. brutia. Physiological and ecological approach (in Greek). PhD Thesis, University of Athens, Athens, Greece.

Skordilis A. and Thanos C.A. 1995. Seed stratification and germination strategy in the Mediterranean pines Pinus brutia and $P$. halepensis. Seed Science Research 5: 151-160.

Spanos I.A. 1992. Structure analysis and regeneration of brutia pine in Thasos island (in Greek). PhD Thesis, University of Thessaloniki, Thessaloniki, Greece.

Spanos I.A., Daskalakou E.N. and Thanos C.A. 2000. Postfire, natural regeneration of Pinus brutia forests in Thasos island, Greece. Acta Oecologica 21: 13-20. 
Thanos C.A. 1999. Fire effects on forest vegetation, the case of Mediterranean pine forests in Greece. In: Eftichidis G., Balabanis P. and Ghazi A. (eds), Wildfire management. Proceedings of the Advanced Study Course on Wildfire Management held in Marathon, Greece, 6-14/10/1997. Algosystems and European Commission DGXII, Environment and Climate Programme, Athens, pp. 323-336.

Thanos C.A. 2000. Ecophysiology of seed germination in Pinus halepensis and P. brutia. In: Ne'eman G. and Trabaud L. (eds), Ecology, Biogeography and Management of Pinus halepensis and $P$. brutia Forest Ecosystems in the Mediterranean Basin. Backhuys Publishers, Leiden, The Netherlands, pp. 37-50.

Thanos C.A. and Daskalakou E.N. 2000. Reproduction in Pinus halepensis and P. brutia. In: Ne'eman G. and Trabaud L. (eds), Ecology, Biogeography and Management ofPinus halepensis and P. brutia Forest Ecosystems in the Mediterranean Basin. Backhuys Publishers, Leiden, The Netherlands, pp. 79-90.

Thanos C.A. and Marcou S. 1991. Post-fire regeneration in Pinus brutia forest ecosystems of Samos island (Greece): 6 years after. Acta Oecologica/Oecologia Plantarum 12: 633-642.

Thanos C.A. and Marcou S. 1993. Natural regeneration of Pinus brutia forests in Samos island. Key events during the first 10 years of the postfire period. In: Papers of International Symposium on Pinus brutia Ten. Secretariat of the Organizing Committee (ed.), Ministry of Forestry (Turkey), Marmaris, 18-23 October 1993, pp. 176-183.

Thanos C.A. and Skordilis A. 1987. The effects of light, temperature and osmotic stress on the germination of Pinus halepensis and $P$. brutia seeds. Seed Science Technology 15: 163-174.
Thanos C.A., Marcou S., Christodoulakis D. and Yannitsaros A. 1989. Early post-fire regeneration in Pinus brutia forest ecosystems of Samos island (Greece). Acta Oecologica/Oecologia Plantarum 10: 79-94.

Thanos C.A., Daskalakou E.N. and Nikolaidou S. 1996. Early postfire regeneration of a Pinus halepensis forest on Mount Parnis, Greece. Journal of Vegetation Science 7: 273-280.

Trabaud L. 1988. Survie de jeunes plantules de pin d' Alep apparues après incendie. Studia Oecologica 5: 161-170.

Trabaud L. 2000. Post-fire regeneration of Pinus halepensis forests in the west Mediterranean. In: Ne'eman G. and Trabaud L. (eds), Ecology, Biogeography and Management of Pinus halepensis and P. brutia Forest Ecosystems in the Mediterranean Basin. Backhuys Publishers, Leiden, The Netherlands, pp. 257-268.

Trabaud L., Grosman J. and Walter T. 1985. Recovery of burnt Pinus halepensis Mill. forests. I. Understorey and litter phytomass development after wildfire. Forest Ecology and Management 12: 269-277.

Tsitsoni T. 1997. Conditions determining natural regeneration after wildfires in the Pinus halepensis (Miller, 1768) forests of Kassandra peninsula (North Greece). Forest Ecology and Management 92: 199-208.

Verroios G. and Georgiadis T. 2002. Post-fire vegetation succession: The case of Aleppo pine (Pinus halepensis Miller) forests of Northern Achaia (Greece). Fresenius Environmental Bulletin 11: $186-193$. 